\title{
Levantamento da contaminação por COVID-19 em cirurgiões-dentistas versus
}

\section{professores do Brasil}

\author{
Survey of contamination by COVID-19 in dentists versus professors in Brazil \\ Encuesta de contaminación por COVID-19 en odontólogos versus profesores en Brasil
}

\section{Resumo}

Buscou-se avaliar a contaminação da COVID-19 nos cirurgiões-dentistas que são altamente expostos aos meios de transmissão da doença, comparativamente a professores selecionados dos diferentes níveis da educação. A pesquisa foi aprovada pelo CEP/UFJF - 4.690.509. Trata-se de um estudo transversal quali-quantitativo, com amostra de 133 cirurgiões-dentistas, pareados com professores do ensino fundamental, médio e superior $(\mathrm{n}=68)$ de todo Brasil. A coleta de dados foi conduzida a partir de um questionário autoaplicável (maio a agosto de 2021). Grande parte de ambos profissionais era do sexo feminino, da região Sudeste e apresentaram sintomas relacionados à doença. Enquanto $68 \%$ dos professores estavam em atividade remota exclusiva, $70 \%$ dos cirurgiões-dentistas atendiam em ambientes de clínicas. Houve associação estatística entre as variáveis tipo de exame realizado, resultado do teste e dias de afastamento, considerando-se a profissão $(\mathrm{p}<0,05)$. A contaminação de cirurgiões-dentistas pela COVID-19 é baixa, comparativamente aos professores que estavam majoritariamente em atuação remota. O contato com familiares positivados para o vírus se mostrou presente em grande parte dos profissionais, sugerindo uma contaminação adquirida por parte deles. Com isso, torna-se relevante assumir o compromisso pessoal no combate à propagação da COVID-19 no país, tanto no âmbito social, como profissional por parte de toda população, independente de sua forma de trabalho e os riscos de exposição inerentes a ela.

Palavras-chave: SARS-CoV-2; Odontologia; Controle de Infecção.

\begin{abstract}
We sought to assess the contamination of COVID-19 in dentists who are highly exposed to the means of transmission of the disease, compared to selected teachers from different levels of education. The research was approved by CEP/UFJF - 4,690,509. This is a qualitative-quantitative cross-sectional study, with a sample of 133 dentists, paired with elementary, high and higher education teachers $(n=68)$ from all over Brazil. Data collection was conducted using a self-administered questionnaire (May to August 2021). Most of both professionals were female, from the Southeast region and had symptoms related to the disease. While $68 \%$ of the professors were in exclusive remote activity, $70 \%$ of the dentists worked in clinical environments. There was a statistical association between the variables type of exam performed, test result and days of leave, considering the profession $(p<0.05)$. The contamination of dentists by COVID-19 is low, compared to teachers who were mostly working remotely. Contact with family members positive for the virus was present in most professionals, suggesting contamination acquired by them. With this, it becomes relevant to assume a personal commitment to combat the spread of COVID-19 in the country, both in the social and professional spheres by the entire population, regardless of their way of working and the risks of exposure inherent to it.
\end{abstract}

Keywords: SARS-CoV-2; Dentistry; Infection Control. 


\section{Resumen}

Buscamos evaluar la contaminación de COVID-19 en dentistas que están altamente expuestos a los medios de transmisión de la enfermedad, en comparación con profesores seleccionados de diferentes niveles de educación. La investigación fue aprobada por CEP/UFJF - 4.690.509. Se trata de un estudio transversal cualitativo-cuantitativo, con una muestra de 133 odontólogos, emparejados con profesores de enseñanza básica, media y superior ( $\mathrm{n}=68$ ) de todo Brasil. La recolección de datos se realizó mediante un cuestionario autoadministrado (mayo a agosto de 2021). La mayoría de ambos profesionales eran del sexo femenino, de la región Sudeste y presentaban síntomas relacionados con la enfermedad. Mientras que el $68 \%$ de los profesores se encontraban en actividad exclusiva a distancia, el $70 \%$ de los odontólogos trabajaban en ambientes clínicos. Hubo asociación estadística entre las variables tipo de examen realizado, resultado de la prueba y días de licencia, considerando la profesión $(p<0,05)$. La contaminación de los dentistas por COVID-19 es baja, en comparación con los maestros que en su mayoría trabajaban de forma remota. El contacto con familiares positivos para el virus estuvo presente en la mayoría de los profesionales, sugiriendo contaminación adquirida por ellos. Con ello, cobra relevancia asumir un compromiso personal para combatir la propagación del COVID-19 en el país, tanto en el ámbito social como profesional por parte de toda la población, independientemente de su forma de trabajo y los riesgos de exposición inherentes a la misma.

Palabras clave: SARS-CoV-2; Odontología; Control de infección.

\section{Introdução}

O novo coronavírus SARS-CoV-2 (síndrome respiratória aguda grave coronavírus 2), causador da doença pandêmica conhecida como COVID-19 (doença do coronavírus de 2019), que é transmitida principalmente através do contato entre pessoas, tem afetado profundamente o mundo. Organizações como o Centro para Controle e Prevenção de Doenças (CDC) e a Organização Mundial da Saúde (OMS) desenvolveram listas de preparação e prevenção em relação à contenção da propagação de COVID-19, para serem usadas pelo público em geral e profissionais de saúde (CDC, 2020; OMS 1, 2020).

Como as informações sobre a transmissão do SARS-CoV-2 surgiram durante os estágios iniciais da pandemia, a preocupação com a transmissão de partículas transportadas pelo ar contendo vírus no consultório odontológico se tornou ainda mais relevante, tendo em vista que o risco de infecção cruzada em Odontologia é considerado alto (Volgenant \& De Soet, 2018). Sabe-se que respingos e aerossóis produzidos durante os tratamentos odontológicos de rotina, combinados com a proximidade física da face do paciente, aumentam o risco (Peng, et al., 2020).

Inicialmente consultórios odontológicos foram fechados e foi orientado o adiamento de tratamentos odontológicos para pacientes com COVID-19 ou com suspeita de infecção pelo vírus, exceto em casos de urgência. Porém, com o passar do tempo os mesmos voltaram a fornecer atendimentos de rotina, possibilitando o aumento da disseminação da infecção na comunidade (Hodge, 2020).

O fechamento de escolas também fez parte da resposta à pandemia na maioria dos países. Embora a duração e a extensão dos fechamentos tenham variado, crianças, jovens e professores tiveram acesso limitado às mesmas (OWD, 2021). Em todo o mundo, foi-se levando em conta os riscos e benefícios do fechamento de escolas. Entre as considerações complexas estava se o ensino presencial representa um risco maior para os professores (Vlachos et al.,2020).

No Brasil, o Instituto Nacional de Estudos e Pesquisas Educacionais Anísio Teixeira (Inep) desenvolveu um formulário específico com o intuito de coletar informações sobre a situação e as estratégias adotadas pelas escolas, do ano letivo de 2020. O levantamento mostrou que 99,3\% das escolas brasileiras suspenderam as atividades presenciais. O percentual de escolas que não retornaram às atividades presenciais no ano letivo de 2020 na rede federal, foi de 98,4\%, seguido pelas escolas municipais $(97,5 \%)$, estaduais $(85,9 \%)$ e privadas (70,9\%). Diante desse contexto, mais de $98 \%$ das escolas do País adotaram estratégias não presenciais de ensino (Brasil, 2021).

Embora já tenha sido apresentado pela literatura que os dentistas do Brasil apresentam taxa de infecção por COVID19 similar à população em geral (Ferreira, et al., 2021), conhecer como o SARS-CoV-2 pode impactar a Odontologia no Brasil, comparando-se o risco de contaminação por COVID-19 com outro profissional que se manteve em trabalho remoto durante o mesmo período se faz importante. Diante do exposto, buscou-se avaliar a contaminação da COVID-19 nos cirurgiões-dentistas 
que são altamente expostos aos meios de transmissão da doença, comparativamente a professores selecionados dos diferentes níveis da educação. Dessa forma, tendo os professores como grupo controle, a hipótese é que os cirurgiões-dentistas do Brasil mesmo se expondo mais, se contaminam menos, porque seguem mais protocolos de biossegurança.

\section{Metodologia}

O estudo foi aprovado pelo Comitê de Ética em Pesquisa - Universidade Federal de Juiz de Fora (CEP/UFJF), tendo como número do parecer: 4.690.509. Todos os participantes concordaram com o Termo de Consentimento Livre e Esclarecido (TCLE).

\section{Desenho do estudo}

Foi realizado um estudo transversal quali-quantitativo com uma amostra de conveniência de cirurgiões-dentistas, de ambos os sexos, que atendem no território nacional. A coleta de dados foi conduzida de maio a agosto de 2021 . Esses profissionais foram pareados com professores do ensino fundamental, médio e superior de todo Brasil, uma vez que estes atuaram desde o início da pandemia de forma remota, pelo menos até o final de 2020 (CNE/CP n 19/2020). Logo, são profissionais que estariam menos expostos profissionalmente à contaminação pelo SARS-CoV-2, comparativamente aos cirurgiões-dentistas que estão constantemente expostos a aerossol de cavidade bucal.

Foram incluídos na amostra os indivíduos com idade $\geq 18$ anos, cirurgiões-dentistas que apresentavam registro no Conselho Regional de Odontologia (CRO) de seu estado e professores do ensino fundamental, médio e superior em atuação. Foram excluídos da amostra, os profissionais que não estavam atuando durante o período de pandemia e que não responderem completamente o questionário. Para professor, as aulas mesmo que remotas foram consideradas em atuação.

Os participantes foram recrutados aleatoriamente, pela estratégia de bola de neve, sendo que inicialmente a equipe de pesquisa enviou o link do questionário para os profissionais de sua região, pedindo que os mesmos divulguem nas suas mídias também. Além disso, foi solicitado, por meio dos e-mails dos Conselhos Regionais de Odontologia do Brasil, a divulgação da pesquisa para os diversos profissionais do país.

\section{Desenho do questionário}

Para a coleta de dados, foi utilizado um questionário estruturado elaborado pelos pesquisadores, com base no utilizado por Santos et al. (2021), e enviado para os participantes, por meio de um link do Google Forms, via e-mail e mídias sociais.

Dois questionários distintos foram elaborados, para os cirurgiões-dentistas e professores, sendo que ambos possuíam 17 perguntas, divididas em duas seções. A primeira sessão para caracterizar os participantes: dentistas - sexo, idade, especialidade, estado que atua, número de registro no $\mathrm{CRO}$, aonde atende. Professores - nome, sexo, idade, nível de escolaridade que leciona, estado que atua e aonde trabalha.

A segunda sessão para adquirir informações acerca da epidemiologia da COVID-19, foi questionado sobre: dentistas uso da máscara N95 e sua reutilização, contato com parente testado positivo para a doença (parentesco, convívio e profissão do mesmo), presença de sintomas e quais, procura de orientação médica, realização de teste, qual tipo e o resultado, se houve afastamento do trabalho. Professores - forma de trabalho durante a pandemia, contato com parente testado positivo para a doença (parentesco, convívio e profissão do mesmo), presença de sintomas e quais, procura de orientação médica, realização de teste, qual tipo, período e o resultado, se houve afastamento do trabalho.

\section{Análise de dados}

Foi utilizado o Microsoft Excel 2019 (Microsoft Corporation, Redmond, Washington, EUA) para a transcrição dos 
dados e para a realização da análise estatística e análises descritivas, que foram feitas com medidas absolutas e de frequências. Foi estabelecida associação entre variáveis categóricas por meio do teste Qui-quadrado com correção de Monte-Carlo, quando necessário. O nível de significância adotado foi de $5 \%(\mathrm{p}<0,05)$.

\section{Resultados}

Um total de 133 e-questionários de cirurgiões-dentistas foram obtidos, sendo que sete questionários foram excluídos por duplicidade de resposta. Nestes casos foi incluído somente o primeiro questionário respondido. Portanto, foram consideradas 126 respostas válidas. Houve respostas de profissionais de todas as regiões brasileiras, destacando-se as regiões Nordeste (50\%) e Sudeste (43\%).

A maioria dos participantes era do sexo feminino (70,6\%), de 36 a 45 anos (33\%) e trabalhava em consultórios privados $(30,2 \%)$ ou rede pública $(25,4 \%)$. As especialidades dos participantes foram agrupadas em cinco categorias, de acordo com a relação entre especialidade odontológica. Grupo 1 - Clínico Geral, Prótese, Odontogeriatria; Grupo 2 Implantodontia, Periodontia, Cirurgia Oral, Endodontia; Grupo 3 - Pacientes com Necessidades Especiais, Odontologia Hospitalar, Estomatologia, Dor Temporomandibular; Grupo 4 - Ortodontia, Radiologia Oral, Ortopedia Facial e Grupo 5 Odontopediatria e Saúde Pública. Dentro destes grupos, o número 1 foi o mais representativo (32,5\%) - tabela 1.

Um total de 69 e-questionários de professores foram obtidos, sendo que um participante respondeu mais de uma vez e somente o primeiro questionário foi considerado. Portanto, foram consideradas 68 respostas válidas. Houve respostas de professores apenas de três regiões brasileiras, destacando-se o Sudeste (88\%) e nenhuma das regiões Norte e Centro-Oeste.

A maioria dos participantes era do sexo feminino (86,8\%), de 36 a 45 anos $(42,6 \%)$ e trabalhava na rede pública (69\%). Foi questionado sobre o nível de escolaridade que lecionavam, viu-se que grande parte dos respondentes eram professores do ensino superior (39,7\%). Durante a pandemia, até agosto de 2021 (término da coleta de dados), a maioria trabalhou apenas de forma remota $(67,6 \%)$ e somente $13,2 \%$ já havia voltado para o modelo presencial - Tabela 1.

Em relação aos questionamentos sobre uso de máscaras pelos cirurgiões-dentistas, durante os atendimentos, independente do procedimento realizado, $73,8 \%$ dos profissionais relatou utilizar máscaras do tipo N95. Sendo que $44,4 \%$ a reutilizava mais de quatro vezes.

De todos os dentistas respondentes, grande parte $(74,6 \%)$ afirmou que teve contato com parentes que testaram positivo para COVID-19. Foi questionado sobre o grau de parentesco, convívio e profissão da pessoa, porém 32,3\% responderam de forma incompleta e dos que responderam os três questionamentos, a maioria $(24,7 \%)$ possuía grau de parentesco próximo, como marido/mulher e filhos, que tinha convívio constante e os quais eram profissionais da saúde (dentistas e médicos) e funcionários do comércio.

Grande parte dos professores $(82,4 \%)$ afirmou que teve contato com parentes que testaram positivo para COVID-19. Sobre o grau de parentesco, convívio e profissão da pessoa, 39,3\% responderam de forma incompleta e dos que responderam os três questionamentos, a maioria $(21,4 \%)$ possuía grau de parentesco próximo, tinha convívio constante. 
Tabela 1 - Dados demográficos dos cirurgiões-dentistas e professores participantes do estudo para levantamento da contaminação por COVID-19 no Brasil.

\begin{tabular}{|c|c|c|c|c|c|c|}
\hline \multicolumn{7}{|c|}{ Cirurgiões-dentistas } \\
\hline Variáveis & \multicolumn{6}{|c|}{ Participantes n $(\%)$} \\
\hline \multirow[t]{2}{*}{ Sexo } & Masculino & Feminino & & & & \\
\hline & $37(29,4)$ & $89(70,6)$ & & & & \\
\hline \multirow[t]{2}{*}{ Idade (anos) } & $18-25$ & $26-35$ & $36-45$ & $46-55$ & $56-65$ & Acima de 65 \\
\hline & $17(13,5)$ & $38(30,2)$ & $42(33,3)$ & $22(17,5)$ & $5(4)$ & $2(1,5)$ \\
\hline \multirow[t]{2}{*}{$\begin{array}{l}\text { Grupos de } \\
\text { especialidades } \\
\text { odontológicas }\end{array}$} & $\begin{array}{c}\text { Grupo 1: } \\
\text { Clínico Geral, } \\
\text { Prótese, } \\
\text { Odontogeriatria }\end{array}$ & $\begin{array}{l}\text { Grupo 2: } \\
\text { Implantodontia, } \\
\text { Periodontia, } \\
\text { Cirurgia Oral, } \\
\text { Endodontia }\end{array}$ & $\begin{array}{c}\text { Grupo 3: } \\
\text { Pacientes com } \\
\text { Necessidades } \\
\text { Especiais, } \\
\text { Odontologia } \\
\text { Hospitalar, } \\
\text { Estomatologia, Dor } \\
\text { Temporomandibular }\end{array}$ & $\begin{array}{c}\text { Grupo 4: } \\
\text { Ortodontia, } \\
\text { Radiologia } \\
\text { Oral, } \\
\text { Ortopedia } \\
\text { Facial }\end{array}$ & $\begin{array}{c}\text { Grupo 5: } \\
\text { Odontopediatria } \\
\text { e Saúde Pública }\end{array}$ & $\begin{array}{c}\text { Não tem a } \\
\text { especialidade }\end{array}$ \\
\hline & $41(32,5)$ & $34(27)$ & $4(3,2)$ & $25(19,8)$ & $15(11,9)$ & $7(5,6)$ \\
\hline \multirow{2}{*}{$\begin{array}{l}\text { Região } \\
\text { brasileira }\end{array}$} & Norte & Nordeste & Sudeste & Sul & Centro-oeste & \\
\hline & $2(1,6)$ & $63(50)$ & $54(42,9)$ & $4(3,1)$ & $3(2,4)$ & \\
\hline \multirow[t]{2}{*}{$\begin{array}{l}\text { Condição de } \\
\text { trabalho }\end{array}$} & $\begin{array}{c}\text { Consultório } \\
\text { particular }\end{array}$ & $\begin{array}{c}\text { Clínica } \\
\text { particular }\end{array}$ & Rede pública & $\begin{array}{l}\text { Mais de } \\
\text { uma } \\
\text { condição }\end{array}$ & & \\
\hline & $38(30,2)$ & $24(19)$ & $32(25,4)$ & $32(25,4)$ & & \\
\hline \multicolumn{7}{|c|}{ Professores } \\
\hline Variáveis & \multicolumn{6}{|c|}{ Participantes n $(\%)$} \\
\hline \multirow[t]{2}{*}{ Sexo } & Masculino & Feminino & & & & \\
\hline & $9(13,2)$ & $59(86,8)$ & & & & \\
\hline \multirow[t]{2}{*}{ Idade (anos) } & $18-25$ & $26-35$ & $36-45$ & $46-55$ & $56-65$ & Acima de 65 \\
\hline & $2(2,9)$ & $11(16,2)$ & $29(42,6)$ & $\begin{array}{c}21 \\
(30,9)\end{array}$ & $4(5,9)$ & $1(1,5)$ \\
\hline \multirow[t]{2}{*}{$\begin{array}{l}\text { Nível de } \\
\text { escolaridade } \\
\text { que leciona }\end{array}$} & $\begin{array}{c}\text { Ensino } \\
\text { fundamental } \\
I\end{array}$ & $\begin{array}{c}\text { Ensino } \\
\text { fundamental II }\end{array}$ & $\begin{array}{c}\text { Ensino } \\
\text { fundamental I e II }\end{array}$ & $\begin{array}{l}\text { Ensino } \\
\text { médio }\end{array}$ & $\begin{array}{c}\text { Ensino } \\
\text { fundamental } \\
\text { e médio }\end{array}$ & $\begin{array}{l}\text { Ensino } \\
\text { superior }\end{array}$ \\
\hline & $15(22,1)$ & $2(2,9)$ & $2(2,9)$ & $5(7,4)$ & $17(25)$ & $27(39,7)$ \\
\hline \multirow{2}{*}{$\begin{array}{l}\text { Região } \\
\text { brasileira }\end{array}$} & Norte & Nordeste & Sudeste & Sul & Centro-oeste & \\
\hline & $0(0)$ & $4(5,9)$ & $60(88,2)$ & $4(5,9)$ & $0(0)$ & \\
\hline \multirow[t]{2}{*}{$\begin{array}{l}\text { Condição de } \\
\text { trabalho }\end{array}$} & $\begin{array}{c}\text { Rede } \\
\text { particular }\end{array}$ & Rede pública & $\begin{array}{c}\text { Rede particular e } \\
\text { pública }\end{array}$ & & & \\
\hline & $11(16,2)$ & $47(69,1)$ & $10(14,7)$ & & & \\
\hline \multirow{2}{*}{$\begin{array}{l}\text { Forma de } \\
\text { trabalho na } \\
\text { pandemia }\end{array}$} & Remoto & $\begin{array}{l}\text { Remoto - } \\
\text { Híbrido }\end{array}$ & $\begin{array}{c}\text { Remoto - } \\
\text { Presencial }\end{array}$ & & & \\
\hline & $46(67,6)$ & $13(19,2)$ & $9(13,2)$ & & & \\
\hline
\end{tabular}

Fonte: Dados da pesquisa (2021). 
Para comparação das variáveis categóricas entre dentistas e professores, foram levadas em consideração as questões em comum dos questionários que avaliaram a epidemiologia da COVID-19 nos profissionais. Na Tabela 2 estão expostos os dados referentes à estatística descritiva e inferencial.

Tabela 2 - Dados referentes à epidemiologia da COVID-19 e comparação das variáveis categóricas entre cirurgiões-dentistas e professores do Brasil participantes do estudo.

\begin{tabular}{|c|c|c|c|}
\hline Variáveis & $\begin{array}{c}\text { Cirurgião-dentista } \\
\text { n (\%) }\end{array}$ & $\begin{array}{l}\text { Professor } \\
\text { n }(\%)\end{array}$ & $p$ \\
\hline $\begin{array}{l}\text { Contato com parente positivo } \\
\text { Sim } \\
\text { Não }\end{array}$ & $\begin{array}{l}94(74,6) \\
32(25,4)\end{array}$ & $\begin{array}{l}56(82,4) \\
12(17,6)\end{array}$ & 0,22 \\
\hline $\begin{array}{l}\text { Presença de sintomas } \\
\text { Sim } \\
\text { Não }\end{array}$ & $\begin{array}{l}70(55,6) \\
56(44,4)\end{array}$ & $\begin{array}{l}35(51,5) \\
33(48,5)\end{array}$ & 0,59 \\
\hline $\begin{array}{l}\text { Quantidade de sintomas } \\
\text { Não teve } \\
\text { Até } 2 \\
\text { Acima de } 3\end{array}$ & $\begin{array}{l}56(44,4) \\
33(26,2) \\
37(29,4)\end{array}$ & $\begin{array}{l}33(48,5) \\
17(25,0) \\
18(26,5)\end{array}$ & 0,85 \\
\hline $\begin{array}{l}\text { Tipo de exame realizado } \\
\text { PCR } \\
\text { Sorológico } \\
\text { PCR+Sorológico } \\
\text { Nenhum }\end{array}$ & $\begin{array}{l}24(19,0) \\
48(38,1) \\
21(16,7) \\
33(26,2)\end{array}$ & $\begin{array}{c}8(11,8) \\
21(30,9) \\
5(7,4) \\
34(50,0)\end{array}$ & $\mathbf{0 , 0 1}$ \\
\hline $\begin{array}{l}\text { Resultado do teste } \\
\text { Positivo } \\
\text { Negativo } \\
\text { Não me submeti }\end{array}$ & $\begin{array}{l}32(25,4) \\
61(48,4) \\
33(26,2)\end{array}$ & $\begin{array}{l}17(25,0) \\
17(25,0) \\
34(50,0)\end{array}$ & $\mathbf{0 , 0 0}$ \\
\hline $\begin{array}{l}\text { Afastamento do trabalho } \\
\text { Sim } \\
\text { Não }\end{array}$ & $\begin{array}{c}33(94,3) \\
2(5,7)\end{array}$ & $\begin{array}{l}11(55,0) \\
9(45,0)\end{array}$ & $\mathbf{0 , 0 0}$ \\
\hline $\begin{array}{l}\text { Quantidade de dias de } \\
\text { afastamento } \\
\text { Não foi afastado } \\
7 \text { dias } \\
14 \text { dias } \\
\text { Mais de } 14 \text { dias }\end{array}$ & $\begin{array}{c}2(5,7) \\
3(8,6) \\
19(54,3) \\
11(31,4)\end{array}$ & $\begin{array}{l}9(45,0) \\
4(20,0) \\
4(20,0) \\
3(15,0)\end{array}$ & $\mathbf{0 , 0 0}$ \\
\hline
\end{tabular}

Fonte: Dados da pesquisa (2021).

Dos 126 dentistas, 70 declararam ter sentido sintomas característicos da doença (tosse, febre, dificuldade para respirar, dor no corpo, dor de cabeça), sendo que 29,4\% tiveram mais de 3 desses sintomas. Já dos 68 professores respondentes, 51,5\% declararam ter sentido sintomas, sendo que 26,5\% tiveram mais de 3 desses sintomas, porém não houve associação estatisticamente significativa $(\mathrm{p}>0,05)$ nessas variáveis.

O tipo de exame mais realizado por ambos profissionais foi o sorológico $(38,1 \%$ dentistas e $30,9 \%$ professores). Sendo que quando foi correlacionado a frequências dos diferentes tipos de testes utilizados com o número de participantes em cada classe profissional, houve associação estatística nessa variável ( $\mathrm{p}=0,01$ ). Dos 93 dentistas que foram submetidos a algum teste, $25,4 \%(n=32)$ testaram positivo e 2 deles não interromperam os atendimentos, já com os professores, a metade testou positivo $(n=17)$ e 9 deles não foram afastados do trabalho. Em ambas variáveis - resultado do teste (positivo, negativo ou não foram submetidos a teste) e dias de afastamento (não foram afastados, foram afastados e a quantidade de dias - 7, 14 e mais de 14 dias) houve associação estatisticamente significativa $(\mathrm{p}=0,00)$. 


\section{Discussão}

Sabe-se que a transmissão do SARS-CoV-2 de pessoa para pessoa é por via respiratória e gotículas de saliva ou contato direto com superfícies contaminadas (Chen, et al., 2020). Nesse estudo foi avaliada a epidemiologia da COVID-19 nos cirurgiões-dentistas, que estão em constante contato com aerossóis, comparados com os professores do ensino fundamental, médio e superior, que, em grande parte da pandemia, trabalharam de forma remota, conforme comprovado pelos dados obtidos neste estudo.

No decorrer dos meses do ano de 2020 até agosto de 2021, os casos de infecção por COVID-19 e óbitos novos relacionados à doença se mostraram heterogêneos entre as diferentes regiões do país. Embora nossa pesquisa tenha buscado profissionais, tanto cirurgiões-dentistas quanto professores, de todo o Brasil, a representatividade da região Sudeste, referente aos questionários válidos no nosso estudo, esteve em destaque. Segundo o Ministério da Saúde, na semana epidemiológica 34 (22-28/08/2021), última semana em que foram considerados os questionários recebidos, o Sudeste foi a região com maior número absoluto de casos novos (85.852) e também de óbitos novos no país (2.720) (Ministério da Saúde, 2021). Considerando este dado da epidemiologia da COVID-19 por região brasileira, nota-se que a região Sudeste tem um papel relevante para o perfil da doença quando se considera o país como um todo. Portanto, nossos dados podem ser considerados representativos dos profissionais frente à possibilidade do contato com a doença, já que o maior número de casos de COVID19 e maior parte dos respondentes está nessa região.

Considerando-se o nível de exposição dos profissionais em relação ao SARS-COV-2, observando a forma de trabalho dos professores, sabe-se que as escolas adotaram estratégias não presenciais de ensino (Brasil, 2021), portanto um baixo risco relacionado à profissão. Dos professores respondentes 68\% estavam em atividade remota exclusiva. Portanto, não foram expostos a ambientes fechados com muitas pessoas devido à sua atividade profissional, como as salas de aula. Estavam expostos apenas à rotina de vida cotidiana.

Já os cirurgiões-dentistas $70 \%$ atendiam em ambientes de clínicas públicas e particulares onde a propagação aérea é maior (OMS, 2020), e, portanto, estavam expostos a aerossóis produzidos por outros profissionais. Mesmo diante dessa maior exposição ao aerossol, o uso da máscara N95, que passou a ser considerada um importante EPI (Santos, et al., 2021) nos consultórios odontológicos, se tornou frequente $(73,8 \%)$ no dia-a-dia dos cirurgiões-dentistas participantes deste estudo, porém eles a reutilizam mais de quatro vezes, o que vai contra duas grandes organizações americanas: A American Dental Association - ADA que recomenda apenas uma utilização (ADA, 2020), e o CDC que recomenda o máximo de cinco reusos (CDC 2, 2020). Embora ADA e CDC sejam organizações americanas, as recomendações pelo Conselho Federal de Odontologia (CFO) e Agência Nacional de Vigilância Sanitária (ANVISA) aqui no Brasil, normalmente têm acordo com elas, respectivamente.

Uma outra estratégia de prevenção também muito importante a ser executada para se evitar a propagação da infecção, é evitar contato próximo (menos de $1 \mathrm{~m}$ ) com pessoas, especialmente aquelas com testes positivos e/ou sintomas respiratórios (OMS 1, 2020). Porém, grande parcela, tanto de dentistas quanto professores $(74,6 \%$ e $82,4 \%$, respectivamente), tiveram contato com parentes que testaram positivo para a doença, apesar de não haver diferença estatisticamente significativa $(\mathrm{p}=0,22)$. Logo, foi possível notar que muitos profissionais possivelmente foram expostos à doença em meios diferentes do de trabalho.

O contato com casos positivos, não significa necessariamente o desenvolvimento da doença. Dos participantes, mais da metade (55,6\% dentistas e 51,5\% professores) de ambos profissionais tiveram sintomas $(\mathrm{p}=0,59)$ e mais da metade destes (29,4\% dentistas e $26,5 \%$ professores) tiveram acima de três $(\mathrm{p}=0,85)$ sintomas. Os sintomas mais comuns da COVID-19 são febre, tosse seca e cansaço, sendo que alguns acometidos podem apresentar congestão nasal, dor de garganta ou diarreia. Esses sintomas geralmente são leves e começam gradualmente (Lai, et al., 2020). 
Considerando-se os sintomáticos, em relação àqueles que buscaram orientação médica, houve diferença estatisticamente significativa entre o tipo de exame de confirmação da COVID-19 solicitado e a profissão ( $<<0,05)$, tendo em vista que metade dos professores não o fizeram. O teste RT-PCR foi o menos realizado por ambos, possivelmente pela dificuldade de acesso financeiro ao mesmo, porém como este é considerado padrão ouro na detecção do vírus, com investimentos do Ministério da Saúde, esse teste passou a ser mais acessível no Sistema Único de Saúde (SUS) do Brasil (Ministério da Saúde 2, 2021).

Uma vez feito o exame para confirmação da doença, em relação ao resultado dos testes, os achados desse estudo demonstram que, levando em consideração os profissionais que foram submetidos a algum exame, a maior parte dos dentistas testaram negativo. Isto pode ser justificado pelo fato de que mesmo estando mais expostos, se contaminam menos, porque seguem mais protocolos de biossegurança (Santos, et al., 2021) e as recomendações atuais de controle de infecção (Estrich, et al., 2020), incluindo o uso de máscaras do tipo N95 durante os procedimentos odontológicos. Já em relação aos professores, como a metade não foi testada, possivelmente houve subnotificação dos resultados, dificultando a implementação de políticas públicas para o controle da situação no país (USP, 2020).

Tendo em vista as Portarias Conjuntas $\mathrm{n}^{\circ} 19$ e 20 do Ministério do Trabalho, que, estabelecem medidas a serem observadas visando à prevenção, controle e mitigação dos riscos de transmissão da COVID-19 nos ambientes de trabalho, os profissionais que apresentarem sintomas relacionados à doença, que tiveram contato com alguém positivado ou quando o próprio profissional é um caso confirmado, deve haver um afastamento das atividades presenciais por quatorze dias, devendo ser apresentado documento comprobatório da confirmação (Ministério do Trabalho, 2020). Grande parte dos cirurgiõesdentistas foram afastados do trabalho ao confirmarem a presença da doença e respeitaram os dias mínimos de afastamento, de maneira diferente quando comparados com os professores $(\mathrm{p}=0,00)$. Destaca-se o fato de que dois desses profissionais mantiveram seus atendimentos, mesmo tendo o risco de serem possíveis agentes de transmissão, tanto para os pacientes e equipe, como para a população em geral. Já em relação aos professores, nove deles que não foram afastados, podem ser justificados pelo fato de estarem realizando suas atividades de forma remota, mesmo assim questiona-se seu isolamento social.

De acordo com os achados desse estudo, cirurgiões-dentistas e professores não parecem desempenhar um papel substancial na condução da pandemia de SARS-CoV-2 no Brasil devido ao seu vínculo com a profissão, assim como em outros países (Fenton, et al., 2021; Ismail, et al., 2021; Kirsten, et al., 2021). No entanto, a possível transmissão intrafamiliar se mostrou presente, contradizendo os resultados de outro estudo que pareceu ocorrer muito raramente (Kirsten, et al., 2021).

\section{Conclusão}

A contaminação de cirurgiões-dentistas pela COVID-19 é baixa, comparativamente aos professores que estavam majoritariamente em atuação remota. O contato com familiares positivados para o vírus se mostrou presente em grande parte dos profissionais, sugerindo uma contaminação adquirida por parte deles. Com isso, torna-se relevante assumir o compromisso pessoal no combate à propagação da COVID-19 no país, tanto no âmbito social, como profissional por parte de toda população, independente de sua forma de trabalho e os riscos de exposição inerentes a ela.

\section{Referências}

Brasil. Ministério da Educação. 2021. Divulgados dados sobre impacto da pandemia na educação. https://www.gov.br/inep/pt-br/assuntos/noticias/censoescolar/divulgados-dados-sobre-impacto-da-pandemia-na-educacao.

Centers for Disease Control and Prevention (CDC 1). 2020. Healthcare Personnel Preparedness Checklist for 2019-nCoV. https://www.cdc.gov/coronavirus/2019-ncov/downloads/hcp-preparednesschecklist.pdf.

Centers for Disease Control and Prevention (CDC 2). 2020. Implementing Filtering Facepiece Respirator (FFR) Reuse, Including Reuse after Decontamination, When There Are Known Shortages of N95 Respirators. https://www.cdc.gov/coronavirus/2019-ncov/hcp/ppe-strategy/decontaminationreuse-respirators.html. 
Chen, X., Ran, R., Liu, Q., Hu, Q., Du, X., \& Tan, X. (2020). Hand Hygiene, Mask-Wearing Behaviors and Its Associated Factors during the COVID-19 Epidemic: A Cross-Sectional Study among Primary School Students in Wuhan, China. Int. J. Environ. Res. Public Health, 17(8), 2893.

Estrich, C. G., Mikkelsen, M., Morrissey, R., Geisinger, M. L., Ioannidou. E., Vujicic, M., \& Araújo, M. W. B. (2020). Estimating COVID-19 prevalence and infection control practices among US dentists. J Am Dent Assoc., 151(11), 815-824.

Fenton, L., Gribben, C., Caldwell, D., Colville, S., Bishop, J., Reid, M., White, J., Campbell, M., Hutchinson, S., Robertson, C., Colhoun, H. M., Wood, R., McKeigue, P. M., \& McAllister, D. A. (2021). Risk of hospital admission with covid-19 among teachers compared with healthcare workers and other adults of working age in Scotland, March 2020 to July 2021: population based case-control study. BMJ. 374:n2060.

Ferreira, R. C., Gomes, V. E., Rocha, N. B., Rodrigues, L. G., Amaral, J. H. L., Senna, M. I. B., \& Alencar, G. P. (2021). COVID-19 morbidity among oral health professionals in Brazil. Int Dent J. S0020-6539(21)00101-5.

Hodge, J. G., Jr. Emergency Legal Preparedness: COVID-19. 2020. https://www.networkforphl. org/resources/emergency-legal-preparedness-covid19/.

Ismail, S. A., Saliba, V., Bernal, J. L., Ramsay, M. E., \& Ladhani, S. N. (2021). SARS-CoV-2 infection and transmission in educational settings: a prospective, cross-sectional analysis of infection clusters and outbreaks in England. Lancet Infect Dis, 21(3), 344-353.

Kirsten, C., Unrath, M., Dalpke, A. H., Berner, R., \& Armann, J. (2021). SARS-CoV-2 seroprevalence in students and teachers: a longitudinal study from May to October 2020 in German secondary schools. BMJ Open, 11(6), e049876.

Lai, C., Shih, T., Ko, W., Tang, H., \& Hsueh, P. (2020). Severe acute respiratory syndrome coronavirus 2 (SARS-CoV-2) and coronavirus disease-2019 (COVID-19): the epidemic and the challenges. Int J Antimicrob Agents, 55(3), 105924.

Ministério da Saúde 1. Secretaria de Vigilância em Saúde. 2021. Boletim Epidemiológico Especial 78 - Doença pelo Novo Coronavírus - COVID-19. https://www.gov.br/saude/pt-br/media/pdf/2021/setembro/14/boletim_epidemiologico_covid_78-1.pdf.

Ministério da Saúde 2. 2021. Ministério da Saúde lança Plano Nacional de Expansão da Testagem para Covid-19. https://www.gov.br/saude/ptbr/assuntos/noticias/2021-1/setembro/ministerio-da-saude-lanca-plano-nacional-de-expansao-da-testagem-para-covid-19.

Ministério do Trabalho. 2020. Covid-19 Orientações Empregador e Trabalhador. https://www.gov.br/trabalho-e-previdencia/pt-br/composicao/orgaosespecificos/secretaria-de-trabalho/inspecao/covid-19-1.

Organização Mundial da Saúde (OMS 1). 2020. Coronavirus Disease (COVID-2019) Advice for the Public. https://www.who.int/emergencies/diseases/novelcoronavirus-2019.

Organização Mundial da Saúde (OMS 2). 2020. Infection prevention and control for the safe management of a dead body in the context of COVID-19: interim guidance. Disponível em: https://apps.who.int/iris/handle/10665/331538. Acesso em: 11 dezembro 2021.

Our World in Data (OWD). 2021. School closures during the COVID-19 pandemic. https://ourworldindata.org/grapher/school-closures-covid.

Peng, X., Xu, X., Li,, Y., Cheng, L., Zhou, X., \& Ren, B. (2020). Transmission routes of 2019-nCoV and controls in dental practice. Int. J. Oral Sci, 12(9).

Santos, I. G., Souza, V. G. C., Silva, G. T. V., Lourenço, A. H. T., Laxe, L. A. C., \& Apolônio, A. C. M. (2021). Biosafety in dental practices versus COVID19 outbreak. Pesqui Bras Odontopediatria Clín Integr., 21:e0193.

Universidade de São Paulo (USP). 2020. COVID-19 no Brasil-Análise de Subnotificações. https://ciis.fmrp.usp.br/covid19/analise-subnotificacao/.

Vlachos, J., Hertegård, E., \& Svaleryd, H. (2020). School closures and SARS-CoV-2. Evidence from Sweden's partial school closure. medRxiv. doi:10.13.20211359.

Volgenant, C. M. C., \& De Soet, J. J. (2018). Cross-transmission in the Dental Office: Does This Make You Ill? Curr. Oral Health Rep., 5(4), 221-228. 